Paidéia, 2002, 12(22), 27-37

\title{
AS MULHERES DA FAMÍLIA: MUNDOS PARTILHADOS, MUNDOS EM CONFLITO $^{1}$
}

\author{
Nayara Nascimento Rêgo ${ }^{2}$ \\ Ana Cecilia de Sousa Bastos \\ Miriã Alves Ramos de Alcântara \\ Universidade Federal da Bahia
}

RESUMO: O presente trabalho, de cunho etnográfico, toma como foco de análise o cotidiano de uma família multigeracional, sob a perspectiva de mulheres de três gerações diferentes, que habitam o mesmo teto: avó, mãe e neta. As narrativas sobre eventos cotidianos, principalmente os relacionamentos familiares, colhidas no período de dez anos, revelam aspectos da estrutura complexa da comunicação na família em um mundo partilhado, capaz de produzir sentido, mas também de gerar conflitos. A partir de entrevistas semi - estruturadas com a avó, a mãe e a filha adolescente, foram identificadas condições de risco (violência e abuso de álcool) no âmbito das relações interpessoais. Pode-se inferir que os papéis não são claramente delimitados, o que se expressa no ciclo de transferência de responsabilidades e no exercício da autoridade. A atmosfera é tensa, a violência, já incorporada ao cotidiano, apresenta-se como ponto culminante dos conflitos, enraizada nos relacionamentos, distorcendo as percepções e dificultando a comunicação. Observam-se estratégias através das quais as mulheres continuam se afirmando como eixo em torno do qual a família estrutura seu cotidiano e seus projetos de vida.

Palavras-chave: família, violência, comunicação na família.

\section{THE WOMEN OF THE FAMILY: SHARED WORLDS, WORLDS IN CONFLICT}

ABSTRACT: This work integrates an ethnographic study and the focus is the daily life of a multigenerational family, through the perspective of the three women of the family: grandmother, mother and granddaughter. The narratives about daily events, primarily about family relationships, registered during ten years, reveal aspects of the complex structure of communication. This shared world is able to produce meanings, but also to originate conflicts. From semi-structured interviews with the women: the grandmother, the mother and an adolescent daughter, risk conditions have been identified (violence and alcohol abuse) in the interpersonal relations orbit. It can be deduced that the roles are not well defined, what can be better expressed in the responsibilities transference cycle and authority. The atmosphere is tense, the violence is part of daily life, appears like a culminant point of conflicts, takes root in relationships, changes perceptions and, above all, makes communication difficult. It is possible to observe the strategies through which these women continue to affirm themselves as the center of the family's daily life and its future projects.

Key-words: family, violence, family communication.

O interesse principal do presente estudo é investigar aspectos da família enquanto contexto de desenvolvimento, pelo fato de que no seu interior acontecem as primeiras e cruciais relações sociais

\footnotetext{
' Artigo recebido para publicação em fevereiro de 2002, aceito em julho de 2002.

2 Endereço para correspondência: Nayara Nascimento Rego, Departamento de Psicologia, da Faculdade de Filosofia e Ciências Humanas, Universidade Federal da Bahia, Estrada de São Lázaro, 197, Federação, Salvador Bahia, Cep 402-10730, E-mail nayara_rego@ zipmail.com.br
}

dos sujeitos, aquelas que servirão de base para as demais, além de a família favorecer, em seu cotidiano, o ajuste aos desafios que a vida apresenta, especialmente quando se trata das que vivem situações difíceis, como, por exemplo, a pobreza.

Embora hoje a família, enquanto contexto de desenvolvimento, ou principal 'nicho ecológico', seja alvo de muitas pesquisas, esta sua característica, de acordo com Kreppner e Planck (2000), foi por muito 
tempo negligenciada pela Psicologia do Desenvolvimento. Teorias e estudos sócio-antropológicos já vinham situando a família enquanto espaço de mediação entre o indivíduo e a sociedade; mas é a visão contextualista, tendo como metáfora de raiz o ato em contexto, presente já no pensamento de James, Dewey e G.H. Mead e, mais proximamente, Erving Goffman e Gregory Bateson, que permite tomar como foco principal no estudo do desenvolvimento a mútua dependência entre mudanças no organismo e mudanças no contexto (Lerner, 1991; Mueller \& Cooper, 1986).

Em seu estudo sobre a interdependência entre criança e família na trajetória de desenvolvimento, Kreppner (2000) salienta que, desde muito cedo, as crianças começam a trocar experiências com seus pais e outros membros da família, assim como a reconhecer suas intenções. Há nesse estudo um claro exemplo da dependência que o desenvolvimento tem do contexto, observando-se a criança que se insere no mundo social pelo engajamento em processos essencialmente comunicativos e sendo parte de um meio familiar que se delineia também a partir dessas trocas.

A evolução dos modelos ambientais ou contextuais no estudo do desenvolvimento, cujo início remonta ao final do século XIX, encontra uma importante referência na abordagem de Urie Bronfenbrenner, sendo mais conhecida sua distinção entre micro-sistemas (influências ambientais examinadas dentro de settings singulares ou ao longo de transições ecológicas), meso-sistemas (sistemas de micro-settings, envolvendo relações entre diferentes settings de desenvolvimento, aos quais uma pessoa é afiliada em certo momento), exo-sistema (micro-sistemas, meso-sistemas, estruturas sociais mais amplas que influenciam características de sistemas e indivíduos em níveis mais simples) e macrosistema (estrutura social mais ampla, em termos de valores, normas e sistemas políticos).

Esta primeira formulação vem se ampliando. Recentemente, Bronfenbrenner (1996) preocupa-se mais claramente com a dimensão temporal do contexto, a partir de uma articulação mais clara com a perspectiva do curso de vida propondo um modelo mais amplo: PROCESSO-PESSOA-CONTEXTOTEMPO, particularmente adequado a análises longi- tudinais.

Outros autores (Jacqueline Goodnow, 1995, por exemplo) enfatizam outros critérios na classificação de contextos (dimensões sociais, a participação da pessoa-em-desenvolvimento, e dimensões contratuais). Não menos relevante é a ênfase na mediação simbólica e social, implícita na adoção recente, por Bronfenbrenner (1995) da noção de outro significante (significant others), de G.H. Mead, como dimensão crítica do micro-sistema.

Para Lüscher (1996), o contexto é o lugar de onde $o$ texto emerge, o script em que as narrativas de vida individuais aparecem, de tal modo que, através dos relatos das pessoas, seria possível depreender como elas percebem a influência do contexto e como têm experienciado isso.

Tal concepção está de acordo com a perspectiva co-construtivista, segundo a qual os processos psicológicos superiores são culturalmente construídos, ou seja, só a partir do mundo cultural no qual o sujeito encontra-se inserido é que ele pode construir, ativamente, sua rede de conhecimento e significados. Bastos e Almeida Filho (1999) corroboram esta idéia ao afirmar que:

“(...) os individuos constroem ativamente seus próprios contextos, dentro dos limites socialmente articulados pela cultura e (...) a dinâmica resultante fundamenta-se em práticas coletivas e significativas que o próprio sistema cria para se auto-produzir" (p. 61).

Sendo a família tão central ao processo de constituição subjetiva dos indivíduos, não é de se espantar que um ambiente familiar favorável, flexível às mudanças e que forneça uma base estável para o sujeito, tenda a diminuir a sua vulnerabilidade a fatores de risco e, sabe-se o quanto eventos de crise e estresse persistentes afetam a família e todos os seus membros, representando risco não apenas de disfunção individual, como também podendo gerar conflito relacional e até mesmo ruptura familiar:

"Quanto aos efeitos de experiências difi-
ceis, desde muito cedo se discute até que
ponto podem representar um impacto posi-
tivo ou negativo no curso do desenvolvi- 
mento individual. Na medida em que o envolvimento precoce da criança em situações complexas e emocionalmente excessivas seja promovido na família a partir de eventos que, ao longo do curso de vida, representem disrupção e desafio, este tipo de prática pode ter impacto importante na dimensão vulnerabilidade-resiliência" (Bastos \& Almeida Filho, 1999, p.60).

A abordagem da resiliência familiar tem como objetivo precisamente identificar e fortalecer processos interacionais chave que capacitem as famílias a superar crises e estresse persistente (Walsh, 1998). O conceito de resiliência, ainda em construção, vem se apresentando como uma idéia diretriz capaz de reverter a ênfase no discurso normatizador que a Psicologia herda do modelo médico-patológico, favorecendo a inclusão de novos ângulos através dos quais examinar as trocas entre pessoas e contextos em desenvolvimento. Se, como lembra Walsh (1998), a resiliência ainda é vista por alguns no plano individual, como "traços de personalidade ou estilos de coping que capacitam uma criança ou um adulto a superar experiências de vida" (p. 6), no plano familiar uma visão contextualista se expressa mais claramente, focalizando-se o funcionamento do sistema familiar como um todo. É justamente esse lugar da familia como fonte potencial de resiliência que tem sido negligenciado pela pesquisa.

São poucos os estudos existentes cujo foco investigativo seja a contribuição familiar para a resiliência individual; eles estão muito mais centrados no clima emocional ou na dinâmica de famílias disfuncionais, enfatizando os aspectos patológicos e cegando os pesquisadores acerca dos recursos que podem ser encontrados e fortalecidos nessas famílias, caracterizando-se assim como uma abordagem baseada no déficit.

A orientação de Walsh (1998) é baseada no 'fortalecimento', ou seja, em vez de se concentrar em como e porque as famílias falharam, dirige-se a atenção para como elas conseguiram ser bem sucedidas. Em vez de 'desistir' de famílias problemáticas e resgatar os indivíduos 'sobreviventes', é importante destacar o que há de melhor na família e, a partir de processos-chave, encorajar o crescimento individual e familiar.
O conceito de resiliência torna-se relevante quando se discute a questão das diferenças culturais e individuais nos modos de enfrentamento de condições de risco. Esse construto permite verificar se uma família protagoniza aquilo que sugere Hernandez (1996) como processos característicos: desenvolver forças e capacidades básicas para promover proteção e crescimento a si e a seus membros; desenvolver forças e capacidades específicas para proteger-se de estressores e para promover a adaptação após crises ou transições; beneficiar-se da rede de relações e recursos da comunidade e contribuir com a mesma, especialmente nos momentos de estresses e de crises.

Há outros domínios do funcionamento familiar, segundo Walsh (1998), que se caracterizam, igualmente, como processos familiares chave na resiliência:

- Sistema de crenças: são as crenças que definem nossa realidade. Elas facilitam ou não as ações, e estas, por sua vez, juntamente com suas consequiências, reforçam ou alteram nossas crenças.

- Padrões de organização: Os padrões de organização familiar apóiam a integração da unidade familiar, além de definir os papéis e o que deve ser esperado de cada um.

-Processos de comunicação: É evidente que uma boa comunicação seja favorável a um bom funcionamento familiar, entretanto o termo "boa comunicação" é bastante ambiguo, haja vista as diferenças quanto às percepções e prioridades na comunicação. $\mathrm{O}$ que um pai considera boa comunicação pode não ser, necessariamente, o que seu filho adolescente pensa.

A mesma autora reporta que a comunicação em famílias saudáveis é direta, clara, específica e honesta. As mensagens verbais e comportamentos são consistentes e congruentes, havendo compreensão compartilhada. É a clareza contextual que diferencia realidade $\mathbf{X}$ fantasia, fatos $\mathbf{X}$ opiniões e intenções sérias $\mathbf{X}$ humor. Experiências de crises são mais compreensíveis e administráveis, quando as informações e percepções são compartilhadas, e quando os significados dos eventos e suas implicações para a vida dos membros familiares são discutidos aberta e completamente. 


\section{Nayara Nascimento Rêgo}

Walsh (1998) apresenta ainda o que seria, na acepção de Olson (1993), habilidades na boa comunicação. Entre outras, são citadas: (a) habilidade para falar e ouvir, ou seja, falar diretamente para alguém e ouvir atentamente o que outros dizem; (b) abertura pessoal, que corresponderia a compartilhar sentimentos sobre si mesmo e sobre os relacionamentos; (c) clareza; (d) respeito.

A troca de informações na família é um processo recíproco, em que os familiares enviam mensagens simbólicas e espontâneas, assim como também as recebem, compartilhando, deste modo, aspectos subjetivos uns dos outros, e sentindo-se participantes de uma rede de apoio mútuo. Se a comunicação eficaz favorece, segundo Blechman (1991), transições bem sucedidas, assim como a resolução de problemas normativos e não - normativos, a ineficiência na comunicação, ou seja, os ruídos e mal entendidos só abrem espaço pra um clima estressante e violento, comprometendo o desenvolvimento dos envolvidos.

A resiliência familiar consiste em um processo particular de cada família, mas pode-se dizer que a 'posse' de habilidades comunicacionais, ou melhor dizendo, o estabelecimento de uma comunicação eficiente, facilita o ajuste às dificuldades, na medida em que os membros da família sentem-se compreendidos e apoiados.

É necessário ainda enfatizar, na mesma direção que Walsh (1998), que todas as famílias têm potencial para resiliência, podendo-se maximiza-lo pelo encorajamento de seus melhores esforços e pelo fortalecimento dos processos - chave anteriormente mencionados. Ao falar de família, deve ser dissipada a errônea idéia de que existe a que é normal, classificada como livre de problemas, além do mito de que o modelo da família tradicional é o único capaz de favorecer um ambiente saudável. Famílias com as mais diversas configurações podem ser bem sucedidas, porque não é a estrutura delas, mas são os processos que levam a um funcionamento saudável e à resiliência.

Evidentemente, a estrutura familiar pode favorecer ou não processos mais saudáveis, sendo este mais um ponto que revela a estreita ligação entre desenvolvimento (individual ou familiar) e contexto cultural. Um exemplo: as mudanças por que passa a família no Brasil apontam para uma característica destacada que é o crescente aumento das que são chefiadas por mulheres, tidas como as mais vulneráveis a uma conjuntura de pobreza e desemprego (Brandão Lopes \& Gottschalk, 1990).

Entre as famílias mais pobres, Woortmann (1987), em um trabalho que se tornou referência, $A$ família das mulheres, constata que o sistema de parentesco e a definição de papéis sexuais diferem sensivelmente do padrão de dominância masculina encontrado na família tradicional das classes médias e dominantes. Os pontos focais do sistema de parentesco são justamente as relações mãe-filhos, baseadas em um princípio de reciprocidade generalizada. A percepção da presença masculina, segundo esse autor, indica os homens como transitórios, sendo as mulheres as principais constantes do grupo familiar, inclusive do ponto de vista econômico.

Essa espécie de "dominância feminina" não corresponde necessariamente a um reconhecimento de direitos e a uma ampliação das alternativas de escolha reservadas à mulher. A literatura sociológica sobre a família no Brasil documenta fartamente essa aparente contradição. No âmbito da psicologia há o exemplo das análises da divisão de trabalho no cotidiano doméstico, anteriormente conduzidas por Bastos (2001), mostrando que a mulher é presa do ritmo intenso de trabalho, de uma jornada múltipla, para garantir o atendimento de necessidades básicas, não lhes restando tempo ou energia para priorizar a si e para re-equacionar os termos de suas relações com filhos e companheiros. Não é de estranhar, portanto, que prevaleçam concepções tradicionais de autoridade e de maternidade, no sentido indicado por Trindade (1999):

"O modelo tradicional da maternidade implica em uma figura feminina responsável pela manutenção do vínculo familiar. Esta tarefa deve ter prioridade sobre suas necessidades pessoais, visto que é através da maternidade que se concretizará sua identidade como mulher" ( $\mathrm{p} .33$ ).

A resiliência é forjada, portanto, em uma teia de relacionamentos, significados e experiências ao longo do curso de vida e através das gerações. Esses relacionamentos e experiências são culturalmente estruturados, neles sintetizando-se influências dos 
vários níveis do contexto (proximal e distal), razão porque tanto a perspectiva ecológica quanto a desenvolvimental são essenciais para a compreensão do fenômeno.

Sob esta perspectiva, serão focalizadas as discrepâncias nas narrativas das diferentes mulheres, obtidas ao longo de um estudo de corte longitudinal, que acompanhou, durante quase uma década, famílias (inicialmente dez, oito ao final) de um bairro popular de Salvador, o Vale das Pedrinhas, sobre os eventos cotidianos e, principalmente os relacionamentos no seu interior. Essas narrativas tiveram o objetivo de caracterizar a organização e estruturação do cotidiano familiar e contexto inicial de socialização. Ao analisar essas narrativas, espera-se revelar aspectos da estrutura complexa da comunicação na família, no contexto de uma experiência partilhada.

\section{Metodologia}

\section{o Caso}

A família focalizada é do tipo extensiva, composta por mãe, padrasto, quatro filhos e avós maternos, residentes sob o mesmo teto, casa dos avós, em um bairro popular de Salvador. Os sujeitos são mulheres, que representam três gerações: avó (D. Rosa), mãe (Vilma) e a filha (Roseane). Vilma, a filha mais velha de $\mathrm{D}$. Rosa, reside com a mãe desde que se separou do primeiro marido, pai de seus três filhos mais velhos. Recentemente, Vilma teve mais uma filha, de seu atual parceiro ${ }^{1}$.

\section{Procedimentos de Coleta e Análise de Dados}

O recorte da presente investigação foi definido durante a coleta de dados do último período de um estudo longitudinal com nove anos de duração, sendo que de início o trabalho de campo foi intensivo, realizando-se visitas semanais às famílias; nos anos seguintes, a freqüência de contatos foi gradualmente reduzida (para uma base trimestral, quadrimestral, semestral e por fim anual), sendo os mesmos interrompidos por um ano e retomados depois, quando se concluiu o estudo. Considera-se para análise, no presente artigo, o conjunto de dados referentes à família D. Rosa.

Nos primeiros anos do estudo, foram utiliza- das entrevistas com D. Rosa, que representa a primeira geração, e observação de campo, auxiliadas por recursos tais como fotografia e vídeo-gravação. $\mathrm{Na}$ etapa atual, foram realizadas entrevistas semiestruturadas, tendo como informantes-chave mulheres da segunda e terceira gerações, filha e neta de D. Rosa: Vilma e Roseane (com nove anos de idade no início da pesquisa). Observe-se que todos os depoimentos de $\mathrm{D}$. Rosa referem-se às etapas anteriores do estudo: do primeiro ao sétimo ano. $\mathrm{O}$ nono $\mathrm{e}$ último ano foi o único do qual ela não participou, por estar temporariamente ausente durante a realização das entrevistas. Nas falas de Vilma e Roseane será indicado quando se tratar de uma entrevista da etapa atual, para distinguir daquelas de anos anteriores.

Ao longo do estudo longitudinal, a análise de dados foi viabilizada pela categoria "modos de partilhar", proposta a partir do material reunido durante o primeiro ano de contato intensivo com as famílias. Essa categoria permite colocar, em um mesmo olhar analítico, as práticas em curso na família, os significados culturais que acompanham a inserção da criança nessas práticas, e o contexto interativo, incluindo aqui as formas de comunicação entre os membros da família ${ }^{2}$.

$\mathrm{Na}$ etapa atual, foram selecionados, a partir de técnicas de análise de conteúdo, episódios que caracterizam as diferenças nas narrativas da avó, mãe e filha sobre o cotidiano e principalmente sobre os relacionamentos familiares; nas anteriores, os trechos retirados permitem observar continuidades e mudanças na família. Destaque especial foi dado às discrepâncias nas narrativas das diferentes mulheres. $A$ análise dessas discrepâncias orientou-se pela busca de aspectos da estrutura complexa da comunicação na família, com base em uma experiência partilhada, capazes de produzir sentido, mas também de gerar conflitos.

\section{Resultados e Discussão}

Nas primeiras linhas do clássico Guerra e $P a z$, Tolstoi afirma que todas as famílias felizes são iguais; as infelizes, porém, seriam infelizes, cada uma, a seu próprio modo. Essa idéia, ao enfatizar a singularidade das trajetórias de desenvolvimento das fa-

\footnotetext{
${ }^{1}$ Os nomes aqui colocados são fictícios, a fim de que se possa garantir o anonimato dos participantes.

${ }^{2}$ A descrição detalhada encontra-se em Bastos (2001)
} 
mílias, admite-se, ajusta-se muito bem à tarefa de identificar o fenômeno da resiliência nas que enfrentam adversidades. A medida da felicidade, em si mesma, talvez escape a uma análise psicológica; contudo, bem-estar e qualidade de vida não são sinônimos de ausência de problemas e desafios.

Não se pode, ao empreender essa tarefa, transpor o negativo dos rótulos próprios da ênfase sobre o déficit (o contrário do disfuncional, desestruturado...), que pouco ou nada ajudam a compreender a força e a identidade próprias de uma família singular. A utilidade do conceito de resiliência está em marcar a necessidade de produzir descrições que mostrem pontos de força e vulnerabilidade, o modo próprio de fazer valer estratégias de enfrentamento e de, dialeticamente, manejar recursos, a partir dos aspectos sintetizados por Walsh (1998) em: sistema de crenças, padrões de organização, processos de comunicaçã̃o.

Os episódios analisados a seguir descrevem esse cotidiano, narrado por mulheres de três gerações, enfatizando a dinâmica intra-familiar, buscando identificar pontos de tensão e de apoio, sem em nenhum momento rotular a familia ou fazer estimativas deterministas de suas possibilidades de desenvolvimento.

\section{As diferentes narrativas: conflito e partilha}

Na família de D. Rosa, Vilma e Roseane, a dinâmica é marcadamente moldada por conflitos, que já estruturam o cotidiano. Em todas as narrativas, estão presentes descrições de episódios conflitivos, alguns dos quais podem ser de caráter violento, variando apenas a intensidade ou as explicações dadas. Além da violência, outro fator de risco que permeia esse cotidiano é o alcoolismo; ambos servem de ponto de partida para a avaliação dos projetos de vida dessas três personagens.

Rosa é original de Tucano, interior do Estado da Bahia, onde viveu e trabalhou na roça dos pais até completar quinze anos, idade com que resolveu casar "para poder sair de lá (sic)". O trabalho intenso e contínuo marcou sua infância numa família numerosa em que cada criança realizava tarefas de acordo com o reconhecimento de sua competência pela mãe. Esperando ascender sociaimente através de melhor formação ela transferiu sua família para
Salvador. Motivada em continuar seus próprios estudos, pouco incentivados por seus pais e, em seguida, pelos filhos - que achavam o estudo desnecessário na vida já definida da mãe -, ou em criar oportunidades para encontrassem na educação o que não receberam 'de berço', constrói para seus filhos, como valores, a formação escolar e o trabalho:

“(..) pra gente vencer na vida. Quem nasceu rico nasceu, né, quem nasceu em berço de ouro não precisou trabalhar, mas quem não nasceu, e tem vontade de ter alguma coisa tem que trabalhar, né? Agora, se deixar pra morrer Deus não vai jogar de lado, a gente tem que dar duro pra Deus ajudar pra gente ter alguma coisa" (D. Rosa).

A experiência precoce de trabalho intenso e a formulação de um projeto de vida, através da educação, caracterizam o sonho dessa família, sendo visto que o trabalho confere-lhe dignidade afasta a exclusão, oferece melhores condições e garante a sobrevivência. Ao definir sua vida na família, Rosa a percebe como lugar onde tudo é partilhado:

"(...) a gente é tudo junto, um ajuda o outro pra gente vencer, não tem negócio de esconder, de segredo (D. Rosa)".

Esses relatos mostram claramente que ela se encontra posicionada no topo da hierarquia familiar, sendo a representação da força, ditando as regras e práticas, beirando mesmo o autoritarismo, em torno do eixo central de sua vida, que é o trabalho, visto como o único meio de ascensão social. $O$ "tudo junto" de quem fala inclui ela mesma e seus filhos; o marido, funcionário público aposentado e pequeno comerciante, alcoolizava-se quando mais jovem, causando muita preocupação à mulher. Hoje, parou de beber e recolheu-se a um lugar de silêncio: jamais é mencionado e nunca participou das entrevistas, para as quais todos eram convidados.

Mesmo com os filhos adultos, D. Rosa não aceita perder, ou sequer ter diminuída a sua autoridade, deixando bastante claro que a filha Vilma é sua maior preocupação:

"Ai, meu Deus, estou sofrendo tanto com 
essa filha!" (D. Rosa).

Pois, segundo ela, Vilma não assume suas responsabilidades no cuidado aos filhos, nem materiais nem emocionais.

"(...) Ela agora tem que trabalhar, fazer alguma coisa. Fica dizendo, falando sobre os filhos [que vai cuidar deles sozinha], mas no dia que ela sair, ela larga eles sozinhos. Ela não avisa que vai sair, que volta logo ou amanhã ou depois. Ela sai, não dá notícia. Esquece das responsabilidades. Fica fora um dia, dois ou três, e ela não quer nem saber" (D.Rosa).

D. Rosa não vê então alternativa senão tomar esse lugar para si:

“(...) Toda vida fui eu que criei. Eu não agüento mais isso, criar filho e agora neto" (D. Rosa).

Ao reclamar que a filha transparece a idealização do papel de mãe, aquela que é a responsável pela provisão material e, principalmente emocional dos filhos. Mergulha-se numa versão do que Aragão (1983) chamou de "sacralização da maternidade". Ou seja, a mãe é aquela que deve fazer tudo que puder pelos filhos, dar a vida se for preciso.

"Ave Maria, eu matava e morria pelos meus filhos, não tinha nada no mundo que eu enxergasse além dos meus filhos, pra mim meus filhos eram tudo na minha vida, tudo o que faço é pensando neles" (D. Rosa).

D. Rosa assume o cuidado de sua família além da segunda geração, mesmo consciente do quanto isso the custa, dizendo ser louca pelos netos:

"As crianças não tem nada a ver. Eu sou louca por eles."

D. Rosa não esconde as dificuldades que enfrenta para cuidar deles e o peso dessa sobrecarga:

"E numa vida dessas. Se eu ainda tivesse paz. Às vezes tenho vontade de sumir" (Rosa).

Vilma é apresentada, através do relato de sua mãe e de sua filha, como uma figura dependente, discriminada pelo abuso do álcool; apresenta uma perspectiva frágil de melhoria de vida e cuidado dos filhos, projeto tal que não se sustenta, devido às sucessivas crises de alcoolismo, quando ela demanda mais cuidados do que provê. É com desconfiança e, até mesmo falta de respeito, que tanto $D$. Rosa como Roseane referem-se a ela:

"Minha casa vive abandonada com essa louca [Vilma]. No dia de Natal e de Ano, ela trouxe vagabundo pra dentro de casa. Gente que ela não sabe nem quem é.(...)A gente não está agüentando" (D. Rosa).

Nos relatos de Vilma, em todas as entrevistas, é outra família que transparece: ela se mostra uma mãe zelosa:

“(..) Filhos e filhas é uma parte da gente, ai cada um... Eu vou lhe dizer: tem um filho... Pode ser de quem seja, né? Mas passou dentro de você, você teve, você está cuidando, não sei como muitas mães pegam o filho, pegam, eu não entendo isso..." (Vilma, etapa atual).

E aparenta grande interesse em relação ao que acontece com eles

"(...) a gente fica preocupada, não durmo enquanto ela [Roseane] não chega, né não?" (Vilma, etapa atual)

Já nos relatos de Roseane, observa-se que a mãe não cuida direito dos irmãos menores, ficando ela, desde cedo, responsável por isso:

"(...) Eu cuido do meu dever, cuido deles fazerem os deles. Cuido deles irem pra escola de manhã. Eu almoço, vou pra escola, chego de noite, vejo, olho se tem dever pra eles amanhã. Final de semana a gente sai pra passear".(Roseane, aos 9 anos).

No entanto, nas discussões entre a mãe e a 


\section{Nayara Nascimento Rêgo}

avó, quando ocorriam gritos, ameaças e agressão física mútua, Roseane, aos nove anos, interferia defendendo o direito da mãe decidir sobre a vida dos filhos, uma vez que "foi ela quem pariu". Desde pequena (aos sete anos ligava para a avó pedindo ajuda, quando os pais brigavam e a mãe chegava a desaparecer, deixando as crianças sozinhas por dias); até a adolescência, Roseane precisou assumir responsabilidades que não eram suas, inclusive o difícil manejo das situações em que Vilma se encontrava alcoolizada. Esta sobrecarga modifica o seu discurso em relação à mãe, que antes defendia:

“Eu nunca (...) minha mãe sã, nunca levantei a mão pra minha mãe, nunca falei nada, nem xingar nada, mas é minha mãe beber, acontece isso aí, eu não respeito ela em nada, pra mim é pior do que um cachorro" (Roseane, etapa atual).

E assim, a história se repete: como D. Rosa assumiu o lugar de Vilma uma vez, agora é Roseane que tem tal tarefa. O caminho é conflitivo. Por um lado, pode-se perceber que Roseane sacrifica, em parte, as tarefas desenvolvimentais com as quais deveria estar envolvida em sua adolescência; por outro, identifica-se um padrão de transmissão de responsabilidades na família que representa uma continuidade: neste caso, se não de mãe para fitha, de avó para neta.

Vilma descreve uma vida relativamente boa, dentro do contexto de um bairro pobre. Diz não passar por dificuldades financeiras, ter um bom relacionamento com os filhos, assim como manter uma relação amigável com o ex-marido e a atual companheira deste. Quanto ao seu problema com o álcool, pode-se questionar a que função ele estaria atendendo. Roseane nos dá a pista ao ressaltar que sempre que sua avó está para chegar, a mãe começa a beber. Estaria o álcool, neste caso, atuando como uma válvula de escape? Talvez.

Verifica nessa família que o lugar socialmente recomendável para essa mãe, ou seja, cuidar dos filhos, não é efetivamente ocupado por ela. Outros assumem essa função.

Entra-se, então em um círculo vicioso: Vilma encontra-se em uma constante demanda de cuida- dos, outros realizam suas tarefas, ela não acha espaço, bebe. Nos relatos obtidos a partir do estudo inicial, há indícios apontando nesta direção. Exceto pela iniciativa de Roseane, aos nove anos, não foram observadas tentativas no sentido de ajudar Vilma a exercer seu papel de mãe e condutora da própria família, exceto quanto a pedir ajuda aos pesquisadores, sendo frequente D. Rosa solicitar intervenção no sentido de retirar Vilma do ambiente familiar, enquanto que Roseane incluía a mãe no contexto da entrevista e insistia com ela para contar seus problemas:

"Fale de sua vida, mãínha, se você é feliz, se não é..." (Roseane, aos nove anos)

Foram feitas indicações no sentido de que Vilma procurasse o Serviço de Psicologia da Universidade, mas esta nunca tomou esta iniciativa, mantendo-se em seu discurso sóbrio no qual aparecia como mãe cuidadosa e preocupada com os filhos, conforme a expectativa culturalmente posta para o papel materno. É possível que o próprio espaço da pesquisa estivesse identificado por ela como pertencente à sua mãe e fillha - como acontece na sua própria casa.

Roseane, desde pequena, é chamada a intervir nos conflitos, principalmente entre a avó e a mãe, tomando partido de uma ou de outra. Ela resgata dã avó o ideal de ascensão social, deixado um pouco de lado pela mãe; mostra preocupação com os estudos, seus e dos irmãos. O projeto de melhoria de vida funciona como válvula de escape às tensões cotidianas; sair de casa é uma de suas metas principais.

A existência de uma variedade de relacionamentos de apoio é crucial em qualquer idade, mas muitos pesquisadores acabam esquecendo da importância dos irmãos ou outros na rede da família extensiva, enfatizando muito a presença ou a ausência dos genitores. Crianças resilientes em famílias problemáticas frequientemente selecionam e formam vínculos especiais com adultos influentes em seu meio social. O posicionamento de Roseane ao lado da avó talvez se deva tanto ao fato de ter morado um bom tempo com ela, estabelecendo uma forte ligação, mas, principalmente por ser D. Rosa, o ponto de apoio dela, e da família, representando a estabilidade.

Fulmer (1995), comparando os estágios do 
ciclo de vida de famílias de classe média formada por casais que priorizam suas carreiras, retardando a geração de filhos, e as de baixa renda, constatou que, nestas últimas, pode haver conflito entre mães e outros cuidadores, ou seja, pessoas que tomem decisões em relação à criança, mas que não sejam o pai nem a mãe, algumas vezes em conflito com alguma outra pessoa no subsistema executivo da rede familiar.

Em consequiência, a criança recebe diferentes mensagens disciplinares de vários cuidadores, ficando difícil para ela saber a quem respeitar, obedecer, ou eleger como modelo. Esta situação pode ser agravada se a mãe não assume a tarefa de disciplinar os filhos, e principalmente se ela, assim como suas práticas, for alvo das críticas de sua própria mãe, ou seja, a avó das crianças.

A tarefa transicional que aí se apresenta é transferir a autoridade da avó para a mãe; entretanto, os filhos podem mostrar alguma dificuldade em aceitar isto por terem visto a mãe durante muito tempo quase como uma irmã mais velha, se ela for muito jovem, ou por serem criados em outro lugar. O que se observa na família de Rosa é a transferência de autoridade para a neta, literalmente a irmã mais vetha.

Roseane encontra-se, assim, bem no meio de uma disputa, que pode ser colocada como emocional ou mesmo hierárquica:

"Eu morava com minha avó. Nesse tempo mainha bebia e minha avó não queria que eu ficasse com ela. Mainha brigou com minha avó pra ficar comigo, aí minha avó me tomou" (Roseane, etapa atual).

Existe ainda a questão de a mãe, filhos e netos viverem juntos ou à curta distância, o que dificultaria a diferenciação de papéis, havendo uma divisão entre vários cuidadores.

Roseane mantém com a mãe uma relação ambivalente, de aproximação $x$ afastamento:

"Minha mãe sã, ela é uma pessoa maravilhosa. Faz tudo dentro de casa; mas se ela beber..." (Roseane, etapa atual).

Essa "coexistência dos contrários" pode ser analisada sob a perspectiva de Barros (1988). Para essa autora, essa presença de oposições revelaria a tensão de um elemento sobre o outro, o que ela chamou de modalidades tensivas; estas, por sua vez, denotam afetos implícitos no discurso, que imprimem direções aos relacionamentos interpessoais. Roseane foi criada pelos avós e, talvez encare esse fato como se a mãe tivesse "cedido" seu lugar, daí as recriminações de que esta é alvo.

Desse modo, Roseane sente-se responsável por cuidar da mãe, ao mesmo tempo em que a recrimina por seu comportamento "desviante", chegando a dizer que não gosta dela e que ela não é sua mãe de fato. E desabafa:

"Eu não guentei não, nesse dia, acho que eu virei, fiquei até meio excomungada, peguei minha mãe assim pelo cabelo e joguei minha mãe longe" (Roseane, etapa atual).

D. Rosa, Vilma, Roseane. São três gerações, diferentes narrativas e lugares na hierarquia familiar, mas uma perspectiva comum em relação ao papel definidor de cuidar uns dos outros. É possível perceber vivências variadas desse papel: na primeira geração, há uma fusão entre projeto individual e familiar (mesmo que o sonho de estudar seja negado a $D$. Rosa pelos próprios filhos, só sendo realizado nas gerações seguintes). Vilma expressa a diferenciação entre projeto familiar (ter os filhos bem cuidados) e um movimento individual (mesmo destrutivo). Roseane, por sua vez, esboça um projeto pessoal mais ousado de profissionalização (deseja ser advogada), mas já se confronta com demandas familiares (cuidar dos irmãos e da própria mãe) que interferem e dificultam sua realização.

Nos três casos, nota-se uma tendência à naturalização desse cuidar da família como atribuição da mulher.

Familia de mulheres: mundos em conflito, mundos partilhados

As diferentes vozes que constroem as narrativas aqui analisadas têm em comum um sentido de 


\section{Nayara Nascimento Rêgo}

família: de quem é preciso cuidar - prover moradia, assistência aos pequenos, alimentação, supervisão nas tarefas escolares, atenção aos adolescentes e aos membros fragilizados. Mesmo a voz mais distante desse papel, que é a de Vilma, expressa isso. Fica evidente que é esse o lugar que ela ocupa quando sóbria, e especialmente quando D. Rosa se ausenta, em suas freqüentes viagens para o interior, mesmo não legitimado pelos demais, uma vez que a qualquer momento se espera que ela volte a se alcoolizar e a se comportar de modo incompatível com o papel de cuidadora, instalando-se nessa relação com o álcool que pode representar, em grau extremo, a negação de qualquer projeto de desenvolvimento pessoal.

O cuidado da família, sua condução, seu desenvolvimento, aparecem como atribuições das muTheres, cabendo aos homens o papel de contribuir com o sustento, mesmo que, no presente caso, a maior fonte de recursos venha de D. Rosa, que trabalha desde criança e não pode ainda se permitir o merecido repouso.

Diante dos conflitos que se expressam nessa família, não aparecem questionamentos à necessidade de ela ser cuidada, protegida e conduzida em seu projeto de educação e trabalho conjunto. Para isso, não se medem sacrifícios: D. Rosa abre mão do repouso em sua velhice, Roseane abre mão da vida independente, longe de casa, com que sonha. $E$ Vilma retorna sempre de suas transgressões, jamais rompendo efetivamente com aquele núcleo no qual tem tão difícil inserção. E o impacto dessas transgressões, muitas vezes marcadas por violência, é de certa formà amortecido pelos mecanismos de cuidado da família utilizado pelas outras mulheres e que nessas ocasiões conta com o apoio de parentes (filhos de $D$. Rosa que moram em outros bairros) e de vizinhos. Não há registro de recurso a serviços especializados de apoio.

É indispensável ver essa família inserida em um contexto social mais amplo. São diferentes vozes femininas partilhando responsabilidades, sob a autoridade quase hegemônica da mulher mais velha, que é também, mesmo em idade já avançada, a principal provedora do lar. Há uma continuidade no projeto central - formulação da mulher mais velha - atualizado no momento no fato de que a quase totalidade dos filhos e netos estudarem e trabalharem. $O$ cotidi- ano é marcado por múltiplas tensões; no entanto, a família é capaz de manter as suas metas e permanecer coesa, mesmo vivendo em um bairro em que a violência urbana é intensa, afetando a vida de muitos.

Como diria Hernandez (1996), a família de D. Rosa desenvolveu forças e capacidades básicas para promover proteção e crescimento a si e a seus membros, especialmente as crianças e capacidades específicas para se proteger de estressores, promovendo a adaptação após crises ou transições; e beneficiase da rede de relações e recursos da comunidade. contribuindo com ela.

Mesmo com conflitos em casa, a expectativa de ascensão social de D. Rosa, depositada nos filhos e intensamente absorvido por Roseane, demonstra que seus projetos e metas não foram minados pelo clima estressante em que vive.

É em Roseane que a "reserva de resiliência" da família se expressa mais nitidamente. É possivel afirmar que ela foi capaz de realizar uma síntese pessoal entre a consistência da avó, a instabilidade materna e a ausência do pai, lidando com a complexidade de sua família, sem deixar de explorar o mundo social ao seu redor: o namorado, assim como os amigos são altamente valorizados, compondo uma rede social em que ela encontra apoio para resolver seus problemas e dividir suas experiências. Além disso, ela atravessou bem sua vida escolar, e teve uma experiência de trabalho fora de casa (assessorando um candidato a vereador, nas últimás eleições municipais), que, para ela, articula-se a seu projeto de fazer vestibular para Direito. Como mulher da terceira geração, Roseane encontra-se portanto frente a um leque de alternativas mais amplo que o que se apresentava às gerações anteriores. No entanto. é clara a continuidade entre o seu movimento e o projeto de ascensão social tão perseguido pela avó.

Este aspecto, sem dúvida atualizado e singularizado em Roseane, representa talvez o principal ponto de continuidade entre avó e neta: mesmo frente à adversidade, é preciso arquitetar projetos e persistir em sua realização, afirmando, nesse processo, de alguma maneira, a própria identidade. 


\section{Referências Bibliográficas}

Aragão, L.T. de (1983). Em nome da mãe - Posição estrutural e disposições sociais que envolvem a categoria mãe na civilização mediterrânea e na sociedade brasileira. Perspectivas antropológicas da mulher, v.3, pp.109-142. Rio de Janeiro: Zahar Editores.

Barros, D.L.P. de (1988). Teoria do discurso: fundamentos semióticos. São Paulo: Atual.

Bastos, A.C.S. (2001). Modos de Partilhar - A criança e o cotidiano na familia. Taubaté: Cabral Editora Universitária.

Bastos, A.C.S. \& Almeida Filho, M. (1999). Eventos disruptivos, modos de partilhar e trajetórias de desenvolvimento no contexto de famílias vivendo em pobreza. INTERFACES - Revista de Psicologia, 2 (1), pp. 59-71.

Blechman, E.A. (1991). Effective Communication: Enabling Multiproblem Families to Change.Cap.8. Em P. Cowan \& M. Hetherington (Orgs.), Family transitions, pp.219-244. New Jersey: Lawrence Erlbaum Associates, Publishers.

Bronfenbrenner, U. (1996). Developmental ecology through space and time. Cap. 19. Em P. Moen, G.H. Elder, Jr. \& K. Lüsher (Eds). (1995). Examining lives in context. Washington, D.C.: APA

Elder Jr, G.H. (1991). Family transitions, cycles and social changes. Cap.2. Em P. Cowan \& M. Hetherington (Orgs.), Family transitions, pp.219-244. New Jersey: Lawrence Erlbaum Associates, Publishers.

Fulmer, R.H. (1995). Famílias de baixa renda e familias com formação profissional: uma comparação da estrutura e do processo do ciclo de vida Em: B. Carter, M. Mcgoldrick. e col. As mudanças do ciclo de vida familiar - uma estrutura para a terapia familiar. (pp. 468-496). Porto Alegre: Artes Médicas.

Goodnow, J.J. (1996). Differentiating among social contexts: by spatial features, forms of participation, and social contracts. Em P. Moen,
G. H. Elder, Jr. \& K. Lüsher (Eds). Examining lives in context. Washington, D.C.: APA

Hernandéz, A.C. (1996). Familia y adolescencia: indicadores de salud. Manual de aplicacción de instrumentos. Washington, DC. Fundação W. K. Kellogg.

Kreppner, K. (2000). The child and the Family: Interdependence in Developmental Pathways. Psicologia Teoria e Pesquisa, 16 (1), pp. 1122.

Lemer, R,M. (1991). Changing organism-context relations as the basic process of development: a developmental contextual perspective. Developmental Psychology, 27.(1), 27-32.

Lüscher, K. (1996). Homo Interpretans: On the relevance of perspectives, knowledge and beliefs in the ecology of human development. Em P. Moen, G. H. Elder, Jr. \& K. Lüsher (Eds). (1995). Examining lives in context. Washington, D.C.: APA

Mueller, E.C. \& Cooper, C.R. (1986). On conceptualizing peer relations. Process and outcome in peer relations. Orlando: Academic Press.

Trindade, Z. (1999). Concepções arcaicas sobre maternidade e paternidade e seus reflexos na prática profissional. Em: INTERFACES - Revista de Psicologia, 2 (1), Pp. 33-40.

Walsh, F. (1998). Strengthening Family Resilience. The Guilford Family Therapy Series. New York: AP. 